\title{
Development and Evaluation of Herbal Cream of Berberis aristata for its Antibacterial and Antifungal Activity
}

\author{
Megha Tiwari ${ }^{1}$, Mohd Neyaz Ahsan ${ }^{2}$, Pradeep K Sharma ${ }^{1}$, Anzarul \\ Haque $^{3}$ and Sanjar Alam ${ }^{1 *}$ \\ ${ }^{1}$ Department of Pharmaceutics, RV Northland Institute, Greater Noida, India \\ ${ }^{2}$ Department of Medical Laboratory Technology, University Polytechnic, Birla Insti- \\ tute of Technology, Mesra, Ranchi, India
}

${ }^{3}$ College of Pharmacy, Prince Sattam Bin Abdul Aziz University, Alkharj, KSA

*Corresponding Author: Sanjar Alam, Associate Professor, Department of Pharmaceutics,

RV Northland Institute, Greater Noida, India.

DOI: $10.31080 /$ ASPS.2020.04.0562

\begin{abstract}
In the present study, an attempt was made to formulate and evaluate herbal cream of Berberis aristata (B. aristata) for the management of Psoriasis. The study is intended to be carried out because of low cost, lesser or no side effects of herbal formulations and its potent action than the allopathic medication. They therefore provide a viable alternative for psoriasis management. The drug was evaluated on the basis of U.V, FT-IR, and DSC study. The herbal cream formulations were prepared by emulsion based method. The prepared cream was evaluated on the basis of viscosity, spreadability, grittiness, and in-vitro drug release. With altering the ratio of base different release patterns of the drug were observed. With an increase in the base ratio, there was increase in drug release of formulation (F1), while further increase in the base ratio leads to initial burst release but as the time proceeds the release of the drug got decreased due to increase in grittiness and viscosity of the formulation (F2). Also decrease in the base ratio leads to decrease in the drug release of formulation F3. The FT-IR and DSC analysis indicates that there was no interaction between drug and excipients. The in vitro drug release kinetics study depict that drug release mechanism follows Fickian diffusion. The optimized F1 formulation which shows satisfactory in vitro release was tested for anti bacterial and anti fungal property. The zone of inhibition was found to be $24.66 \pm 1.14$ and $20.45 \pm 1.26$ for bacteria and fungi respectively at $250 \mathrm{ppm}$.
\end{abstract}

Keywords: Berberis aristata; Herbal Cream; Emulsion Based Method; Antifungal; Antibacterial Activity; Skin Irritancy Test and Release Models

\section{Introduction}

Psoriasis is a very common, non-infectious, inflammatory skin disease characterized by well defined, distinctive erythematous plaques yielding adherent silvery white scales, which may manifest bleeding points when removed (Auspitz's sign) [1,2]. Psoriasis may affect any cutaneous surface, but the commonest sites are the extensor surfaces of the elbow sand knees, scalp (where scales may become extremely dense) and sacral areas. Precipitation of psoriasis may occur due to trauma (scratching, sunburn or surgical wounds), Kobner phenomenon, stress or genetic predisposition. Men and women are equally affected, but it is more common in white people than in Asians and black people [1].Psoriasis is either benign and localized (hands and feet) or generalized or life threatening, with associated fever, leucocytosis, arthralgias, diffuse cutaneous and mucosal pustules, secondary infection and electrolyte disturbances [3].
Herbal products have been applied to human healthcare for long-established time. The practices continue today because of its biomedical benefits as well as place in cultural beliefs in many parts of world and have made a great contribution towards maintaining human health [4].

Berberis aristata, (family-Berberidaceae) plant is intended to be used in the herbal formulations because of its potent anti psoriatic action (anti inflammatory) due to the presence of active compound berberine. It shows minimum risk of side effects and having great potential for health management. B. aristata contains isoquinoline alkaloids mainly berberine given in figure 1. Other phytoconstituents includes oxyberberine, berbamine, aromaline, kakrachine, palmatine, oxycanthine, taxilamine, and jatrorrhizine, some of the alkaloids are reported as being found in the chloride salt form [5]. 


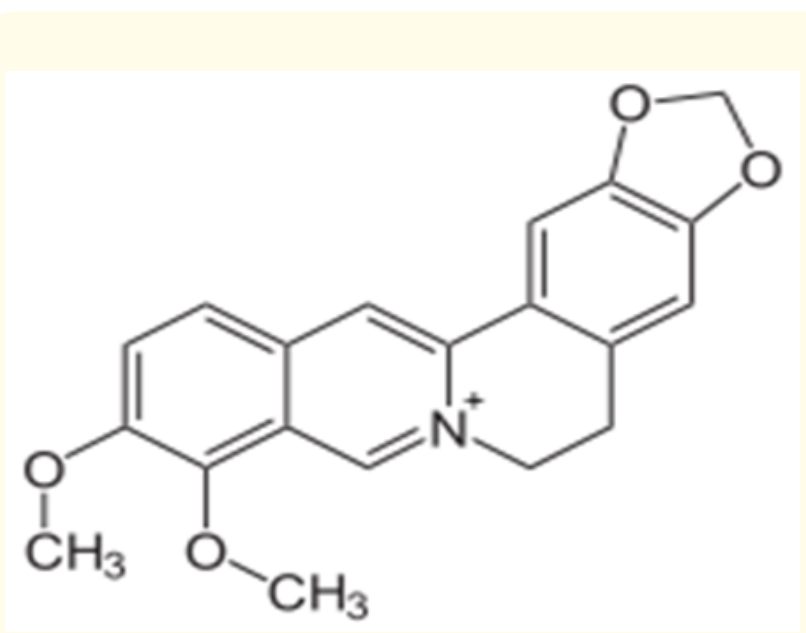

Figure 1: Structure of berberine.

\section{Materials and Method}

- $\quad$ Berberine standard, Berberis aristata extract, Neem seed oil and Camphor was obtained as gift sample from Herbal bioactive lab Jamia Hamdard, New Delhi, India.

- The micro-organisms Bacillus subtilis and Candida albicans was obtained from Microbial cell laboratory and gene bank, Chandigarh, India.

- Stearic acid, Isopropyl myristate, Cetyl alcohol, Triethanolamine, Glycerine, Methyl paraben, Propyl paraben, Salicylic acid, Zinc oxide and Butylated hydroxyl anisole was obtained from Standard chemicals, New Delhi, India.

- All chemicals and reagents used were of analytical grade.

\section{Standardization of Berberis aristata}

The evaluation of a crude drug involves the determination of identity, purity and quality. Purity depends upon the absence of foreign matter whether organic or inorganic, while quality refers essentially to the concentration of the active constituents in the drug that makes it valuable to medicine [6]. Various standardization parameters were evaluated to obtain the qualitative information about the purity and quality of Berberis aristata such as total ash, acid insoluble ash, alcohol soluble extractive, water soluble extractive, foreign matter, melting point, loss on drying [7].

\section{Identification tests}

Identification tests such as Ultraviolet (UV) spectroscopy, Fourier Transform Infrared (FT-IR) spectroscopy, and Differential Scanning Colorimetry (DSC) were conducted.
U.V. spectroscopy method

Preparation of UV plot of berberine in 6.8 phosphate buffer solution

Berberine (from Berberis aristata extract) serial dilutions were made. Initially a solution of the concentration of $1000 \mathrm{mcg} / \mathrm{ml}$ was made by weighing $10 \mathrm{mg}$ of drug using digital balance (Shimadzu, AU X 220) and dissolving in $10 \mathrm{ml}$ of 6.8 phosphate buffer solution. From this stock solution different concentration ranging from 10 $100 \mathrm{mcg} / \mathrm{ml}$ were made in and absorbance of the resulted solution were taken on the PC using 6.8 phosphate buffer solution as blank. The detection wavelength was set at $350 \mathrm{~nm}$ for the detection of Berberine [8]. A graph was plotted between the concentration (Xaxis) and absorbance (Y-axis).

\section{FT-IR method}

FT-IR was obtained using Shimadzu FT-IR spectrophotometer, model iraffinity-1CE. The infra red spectrum of the standard Berberine and drug sample (Berberis aristata extract) was recorded in the range of $800-4000 \mathrm{~cm}^{-1}$ using potassium bromide pellet method and compared for any interactions present $[9,10]$.

\section{Differential scanning calorimetry (DSC)}

DSC of the pure drug was taken by using differential scanning calorimeter [11] (Perkin Elmer DSC-7) calibrated with Indium. All samples were run in triplicate. The instrument was adjusted to the following parameters:

- Atmosphere: Nitrogen inert.

- Heating rate: $10^{\circ} \mathrm{C} / \mathrm{min}$

- Gas flow rate: $20 \mathrm{ml} / \mathrm{min}$

- Temperature range: $30-200^{\circ} \mathrm{C}$

- $\quad$ Sample size: $0.5 \mathrm{mg}$.

Formulation development of anti-psoriatic cream

Oil in water $(\mathrm{O} / \mathrm{W})$ cream (semisolid formulation) was formulated by emulsion-based method. The oil soluble components (Cetyl alcohol, stearic acid, isopropyl myristate, neem seed oil, camphor, salicylic acid, and BHA) were dissolved in the oil phase and heated to $75^{\circ} \mathrm{C}$. The emulsifier (triethanolamine), preservatives (methyl paraben and propyl paraben), and other water soluble components (B. aristata extract and glycerine) were dissolved in the aqueous phase and heated to $75^{\circ} \mathrm{C}$. After heating, the aqueous phase was added in portions to the oil phase with continuous stirring until cooling of emulsifier took place [12]. Then zinc oxide is added slowly to the semisolid with continuous stirring until it is properly blended in it. The formula for the cream is given in table 1 . 


\begin{tabular}{|l|c|c|c|}
\hline \multicolumn{4}{|c|}{ Each 100 gm contains. } \\
\hline \multicolumn{1}{|c|}{ Ingredients } & F1 (gm) & F2 (gm) & F3 (gm) \\
\hline B. aristata extract & 20 & 20 & 20 \\
\hline Stearic acid & 18 & 20 & 16 \\
\hline Isopropyl myristate & 2 & 3 & 1 \\
\hline Cetyl alcohol & 4 & 4.5 & 3.5 \\
\hline Triethanolamine & 2 & 3 & 1 \\
\hline Glycerine & 1 & 1.5 & 0.5 \\
\hline Methyl paraben & 0.95 & 1.4 & 0.5 \\
\hline Propyl paraben & 0.095 & 1 & 0.05 \\
\hline Neem seed oil & 5 & 7 & 3 \\
\hline Camphor & 5 & 6 & 4 \\
\hline Salicylic acid & 2 & 2.5 & 1.5 \\
\hline Zinc oxide & 2 & 2.5 & 1.5 \\
\hline BHA & 1 & 1.5 & 0.5 \\
\hline Water & q.s. & q.s. & q.s. \\
\hline
\end{tabular}

Table 1: Batch design with varying the concentration of base.p

\section{Evaluation parameters of cream}

- Viscosity: Viscosity of the formulation was determined by Brookfield Viscometer at 100 rpm, using spindle no 7.

- $\quad$ pH: The pH meter was calibrated using standard buffer solution. About $0.5 \mathrm{~g}$ of the cream was weighed and dissolved in $50.0 \mathrm{ml}$ of distilled water and its $\mathrm{pH}$ was measured [13] within $24 \mathrm{hrs}$ after formulation.

- Homogeneity: The formulations were tested for the homogeneity by visual appearance and by touch.

- Spread ability: It was determined by wooden block and glass slide apparatus [14]. For the determination of spread ability, excess of sample was applied in between two glass slides and they were compressed to form a uniformly thick layer of cream. The upper slide was then pulled apart horizontally with a string and pulley system. Initially $10 \mathrm{gm}$ weight was tied to the thread and left for 5 minutes, and then the weight was increased by $1 \mathrm{gm}$ at every step. The time required to separate the two slides, i.e. the time in which the upper glass slide moves over the lower plate was taken as measure of Spread ability (S).

Spread ability was calculated by using the formula:

$\mathrm{S}=\mathrm{ML} / \mathrm{T}$, Where,

$\mathrm{S}=$ Spread ability

$\mathrm{M}=$ Weight tied to upper slide

$\mathrm{L}=$ Length moved on the glass slide

$\mathrm{T}=$ Time taken to separate the slide completely from each other.

- $\quad$ After feel: Emolliency, slipperiness and amount of residue left after the application of fixed amount of cream was checked.

- Type of smear: After application of cream, the type of film or smear formed on the skin was checked.

- $\quad$ Removal: The ease of removal of the cream applied was examined by washing the applied part with tap water.

\section{In-Vitro drug release study}

The phosphate buffer with a $\mathrm{pH}$ of 6.8 was used as a receptor medium for the in-vitro drug release studies. The membrane was soaked in phosphate buffer pH 6.8 for 6 - 8 h and was clamped carefully to diffusion cell. The formulated cream $(5 \mathrm{~g})$ was accurately weighed and placed in the donor part of the Franz diffusion cell and a semi permeable cellulose membrane with a molecular cut off point of 1000 . The cell body was filled with degassed phosphate buffer, $\mathrm{pH}=6.8$. The receptor phase was stirred thoroughly by a constantly spinning bar magnate at $100 \mathrm{rpm}$. Intervals of $0.5,1,2$, 4, 6, 8 and $12 \mathrm{hrs}$ were chosen for sampling time [14]. The sample of $5 \mathrm{ml}$ each was withdrawn at predetermined time interval and were replenished immediately with the same volume of phosphate buffer maintaining sink condition throughout the experiment and samples were analyzed for drug content spectrophotometrically at $350 \mathrm{~nm}$.

\section{Release kinetics}

The cumulative drug release obtained from the optimized formulation was used for the calculation of release kinetics i.e. zero order, first order, Higuchi's square root of time equation plot, and Korsmeyer-peppas' power law equation model [14]. All the models are compared for the best fitting of the model.

\section{Anti fungal and anti bacterial screening}

Disc diffusion technique was selected for antifungal and antibacterial activity study. These tests were carried out using cultures of Bacillus subtilis [15,16] and Candida albicans [16] in Sabourauddextrose agar media. An amount of $15 \mathrm{ml}$ (each) of the media with 24-hour subcultures of Bacillus subtilis and C. albicans and was distributed in each petridish (10-cm diameters) respectively and allowed to solidify. On solidification, microbial suspension was spread with the help of sterilized cotton swab on the surface of the 
media. The filter paper disc was prepared from Whatmann's filter paper, which then impregnated with formulation having berberine onto the surface of agar plates, over which a culture of the microorganisms has been streaked. Zone of inhibition diameter ( $\mathrm{mm}$ ) were then recorded [17]. The study was carried out in an aseptic area. The experiment was performed in sterilized condition.

\section{Skin irritation test}

The irritancy of the optimized formulation was determined in the albino Wistar rats procured from R.V. Northland animal house facility (Reg. No. 1149/PO/Ere/S/07/CPCSEA). About 1g cream was applied to the left ear of the albino Wistar rat and the right was considered as a control $[18,19]$. The development of erythema and oedema were monitored for 3 days using the reported method [20].

\section{Results and Discussion}

\begin{tabular}{|l|c|c|}
\hline \multicolumn{1}{|c|}{ Properties } & Observed value & $\begin{array}{c}\text { Reported value } \\
\text { [according to LAB. } \\
\text { monograph] }\end{array}$ \\
\hline Appearance & $\begin{array}{c}\text { Yellowish brown } \\
\text { powder }\end{array}$ & $\begin{array}{c}\text { Yellowish brown } \\
\text { powder }\end{array}$ \\
\hline Taste and odour & $\begin{array}{c}\text { Bitter with aromatic, } \\
\text { characteristic odour }\end{array}$ & $\begin{array}{c}\text { Bitter with aromatic, } \\
\text { characteristic odour }\end{array}$ \\
\hline Melting point & $151.213^{\circ} \mathrm{C}$ & $145^{\circ} \mathrm{C}$ \\
\hline $\begin{array}{l}\text { Loss on drying at } \\
105^{\circ} \mathrm{C}\end{array}$ & $10.5 \%$ & ${ }^{*} \mathrm{NMT} 25 \%$ \\
\hline Total ash & $15.78 \%$ & ${ }^{*} \mathrm{NMT} 28 \%$ \\
\hline Acid insoluble ash & $7.75 \%$ & ${ }^{*} \mathrm{NMT}=15 \%$ \\
\hline $\begin{array}{l}\text { Alcohol soluble } \\
\text { extractive }\end{array}$ & $6.3 \%$ & ${ }^{* *} \mathrm{NLT}=4 \%$ \\
\hline $\begin{array}{l}\text { Water soluble } \\
\text { extractive }\end{array}$ & $36.8 \%$ & ${ }^{* *} \mathrm{NLT}=32 \%$ \\
\hline Foreign matter & $0.68 \%$ & ${ }^{*} \mathrm{NMT}=1 \%$ \\
\hline
\end{tabular}

Table 2: Physico-Chemical Properties of Berberis aristata extract. *NMT: Not More Than; **NLT: Not Less Than.

As shown by the table 2, the physico-chemical properties of the drug was found in accordance with that of standard monograph.

\section{Ultraviolet spectroscopy}

UV plot of berberine in $\mathrm{pH} 6.8$ phosphate buffer solution.

The calibration curve of U. V. depicts that it obeys Beer's Lambert law where, slope $=0.0045$ and $\mathrm{R}^{2}=0.9975$.

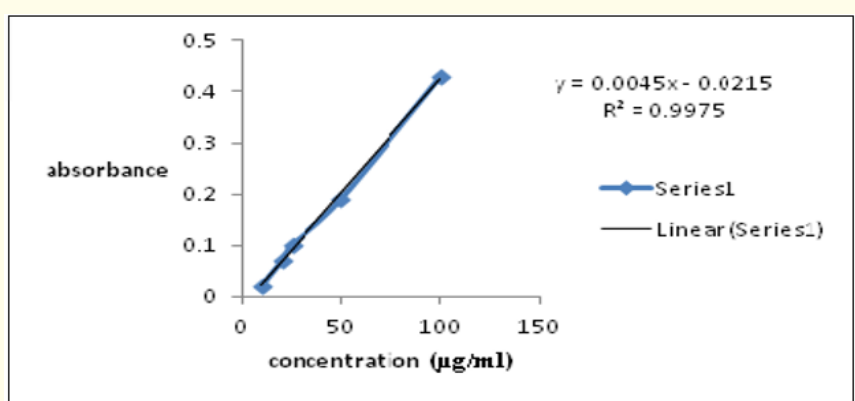

Figure 2: Calibration curve of Berberine through U.V.

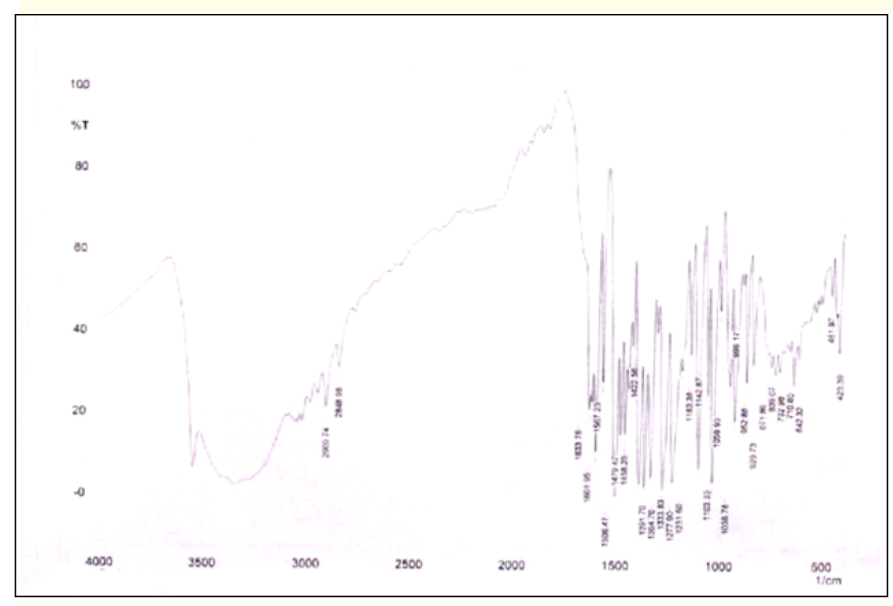

Figure 3: FT-IR Spectra of Berberine in B. aristata extract.

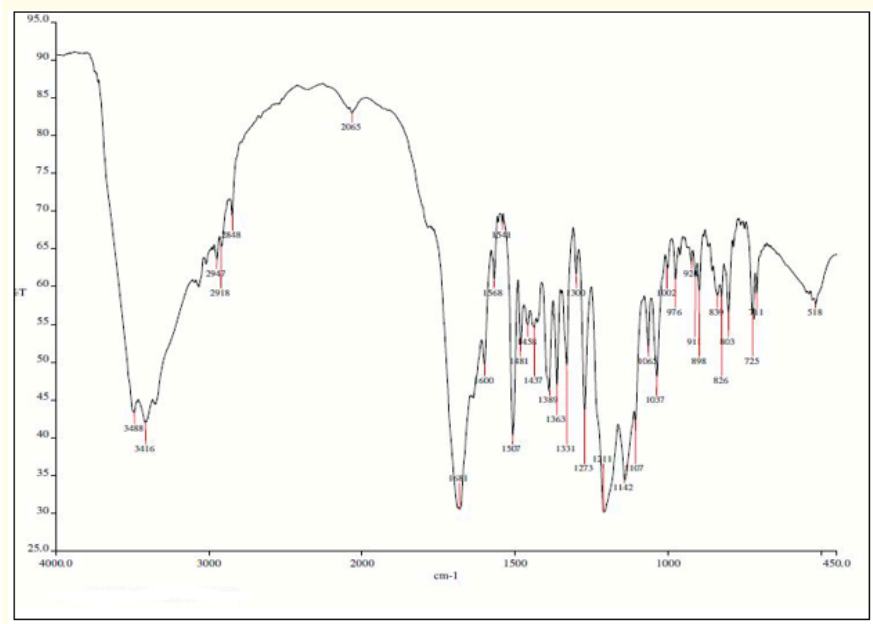

Figure 4: FT-IR spectra of standard Berberine. 
Fourier-transform infrared spectroscopy

\begin{tabular}{|c|c|c|c|c|}
\hline $\begin{array}{l}\text { Wave number } \\
\qquad\left(\mathrm{cm}^{-1}\right)\end{array}$ & $\begin{array}{l}\text { Characteristic functional } \\
\text { group feasible }\end{array}$ & Compound type & $\begin{array}{c}\text { Standard detected at } \\
\left(\mathrm{cm}^{-1}\right)\end{array}$ & $\begin{array}{c}\text { Sample detected at } \\
\left(\mathrm{cm}^{-1}\right)\end{array}$ \\
\hline $2850-2500 \mathrm{~cm}^{-1}$ & Ar C-H stretch & AROMATIC & 2848 & 2848.98 \\
\hline $900-600 \mathrm{~cm}^{-1}$ & $\mathrm{Ar} \mathrm{C} \downarrow \mathrm{H}$ & AROMATIC & 839 & 839.07 \\
\hline $1650-1535 \mathrm{~cm}^{-1}$ & $\mathrm{C}=\mathrm{C}$ stretch & Cyclo alkenes & 1600 & 1601.95 \\
\hline $1690-1520 \mathrm{~cm}^{-1}$ & $\mathrm{C}=\mathrm{N}$ stretch & Heterocyclic amines & 1681 & 1633.78 \\
\hline $1330-1050 \mathrm{~cm}^{-1}$ & C-O stretch & Lactone & 1065 & 1059.93 \\
\hline
\end{tabular}

Table 3: Comparative FT-IR spectra of Berberine extract with standard berberine.

Interpretation of FT-IR

FT-IR interpretation peaks of Aromatic C-H stretch, Aromatic $\mathrm{C} \downarrow \mathrm{H}, \mathrm{C}=\mathrm{C}$ stretch, $\mathrm{C}=\mathrm{N}$ stretch and $\mathrm{C}-\mathrm{O}$ stretch of the sample was found nearly equal to that of standard as shown by the table 3 . Thus, interaction studies depicts that the drug sample was shown to be fairly stable and inert to that of standard used in the formulation.

\section{Differential scanning colorimetry of $B$. aristata extract}

The melting point of the extract was found to be $151.213^{\circ} \mathrm{C}$ which is in accordance with the standard monograph $\left(145^{\circ} \mathrm{C}\right)$ of berberine which confirms the presence of Berberine in the extract of B. aristata.

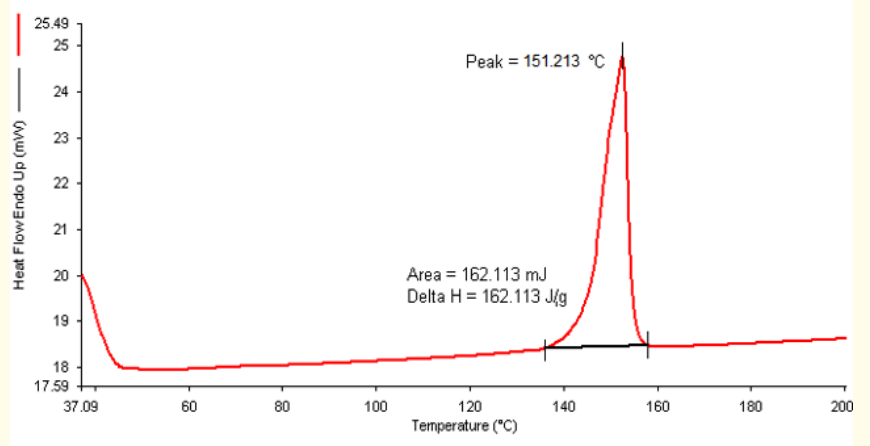

Figure 5: DSC analysis of berberine in B. aristata extract.

As shown in the table 4, there is emolliency and non greasiness in the above formulations F1, F2 and F3 and they are easy in removal. F1 formulation shows $\mathrm{pH}$ similar to that of skin, good homogeneity and high spread ability as compared to formulations F2 and F3. The low viscosity of F1 depicts that the cream is easily spreadable by small amount of shear.

In-vitro drug release study

Drug release from the formulations F1, F2, and F3 shows that F1 formulation has maximum drug release i.e. $76.5 \%$ at $12^{\text {th }}$ hour

\begin{tabular}{|c|c|c|c|}
\hline \multirow{2}{*}{ Parameters } & \multicolumn{3}{|c|}{ Formulation } \\
\cline { 2 - 4 } & F1 & F2 & F3 \\
\hline pH & 6.80 & 5.89 & 5.84 \\
\hline Homogeneity & +++ & ++ & ++ \\
\hline Spread ability & 28.86 & 27.27 & 25.45 \\
\hline Viscosity (cps) & 6800 & 7000 & 7200 \\
\hline After Feel & E & E & E \\
\hline Type of smear & NG & NG & NG \\
\hline Removal & ES & ES & ES \\
\hline
\end{tabular}

Table 4: Evaluation data of formulation F1, F2, F3 for various parameters.

+++: Good; ++: Satisfactory; E: Emollient; NG: Non Greasy; ES: Easy.

\begin{tabular}{|c|c|c|c|}
\hline \multirow{2}{*}{ Time (hrs.) } & \multicolumn{3}{|c|}{ \%CPDR } \\
\cline { 2 - 4 } & F1 & F2 & F3 \\
\hline 0.5 & $30.5 \%$ & $25 \%$ & $23.5 \%$ \\
\hline 1 & $40.5 \%$ & $35.5 \%$ & $30.1 \%$ \\
\hline 2 & $49.5 \%$ & $46.5 \%$ & $36.5 \%$ \\
\hline 4 & $57.5 \%$ & $54.99 \%$ & $43.5 \%$ \\
\hline 6 & $68.5 \%$ & $59 \%$ & $50.5 \%$ \\
\hline 8 & $71.5 \%$ & $60 \%$ & $51.5 \%$ \\
\hline 12 & $76.5 \%$ & $60.5 \%$ & $55.5 \%$ \\
\hline
\end{tabular}

Table 5: Cumulative percent drug release of F1, F2 and F3.

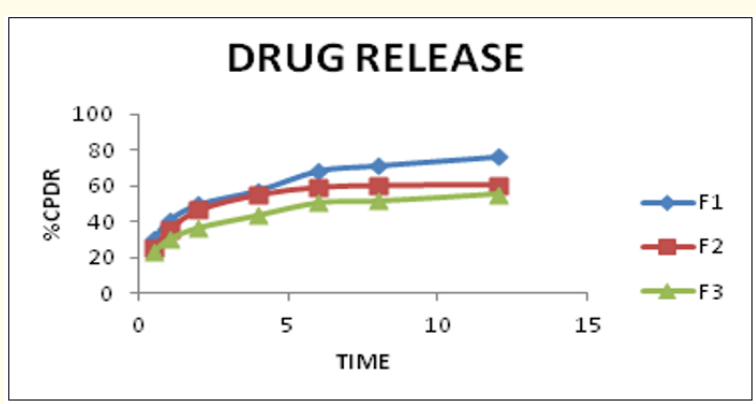

Figure 6: Drug release profile of formulation F1, F2, F3. 
in comparison with the F2 and F3 in which drug release is $60.5 \%$ and $55.5 \%$ respectively.

In-vitro release kinetics study

\section{ZEROORDER}

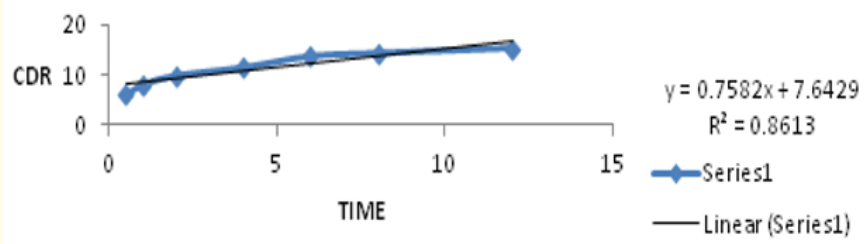

Figure 7: Zero order release kinetics of optimized F1 formulation.

\section{FIRST ORDER}

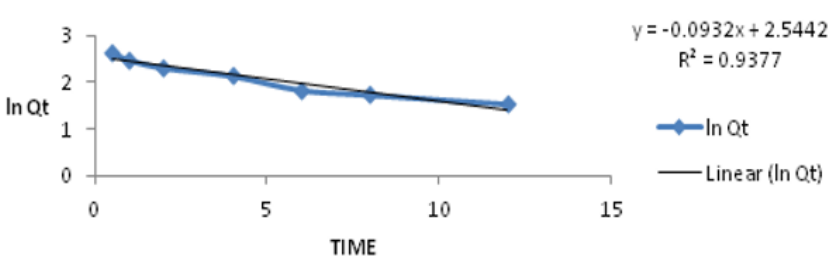

Figure 8: First order kinetics of optimized F1 formulation.

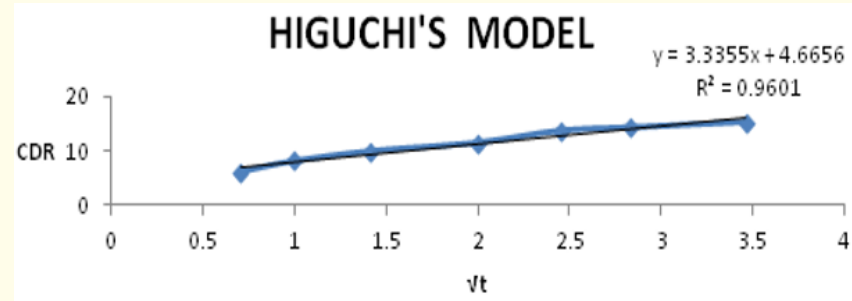

Figure 9: Higuchi's plot of optimized F1 formulation

\section{Korsemeyer peppas model}

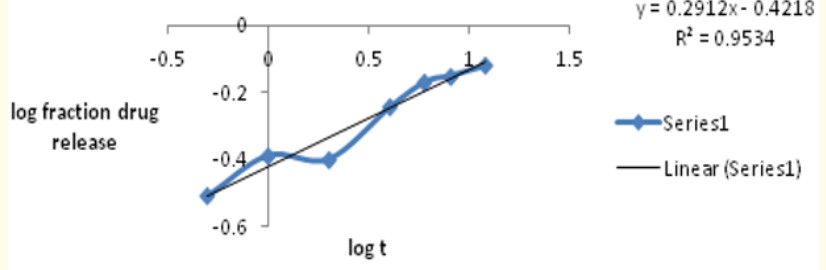

Figure 10: Korsemeyer peppas plot of optimized F1 formulation.

\begin{tabular}{|l|c|c|}
\hline \multicolumn{1}{|c|}{ Release Model } & $\mathbf{R}^{\mathbf{2}}$ & SLOPE=K \\
\hline Zero order model & 0.8613 & 0.7582 \\
\hline First order model & 0.9377 & -0.0932 \\
\hline Higuchi's square root of time plot & 0.9601 & 3.3355 \\
\hline Korsemeyer peppas plot & 0.9534 & 0.2912 \\
\hline
\end{tabular}

Table 6: Model fitting of the drug release profile of formulation F1.

Interpretation of release models (In Vitro)

The formulation so proposed is following first order release kinetics (first order release model, $\mathrm{R}^{2}=0.9377$ ), where drug is being released through diffusion process (Higuchi model $\mathrm{R}^{2}=0.9601$ ). The cream follows Fickian diffusion ( $\mathrm{n}=0.2912$ from KorsmeyerPeppas law equation).

Anti fungal and anti bacterial screening data

\begin{tabular}{|l|c|c|c|c|c|}
\hline Category & \multirow{2}{*}{$\begin{array}{c}\text { Test } \\
\text { organism }\end{array}$} & \multicolumn{4}{|c|}{ Diameter of zone of inhibition (in mm) } \\
\cline { 3 - 6 } & & \multicolumn{4}{|c|}{ Formulation } \\
\cline { 3 - 6 } & & 250ppm/disc & 500ppm/disc \\
\cline { 3 - 6 } & & Cream & *Control & Cream & *Control \\
\hline \multirow{4}{*}{ Bacteria } & Bacillus & $24.66 \pm$ & $6.69 \pm 0.59$ & $26.26 \pm$ & $6.69 \pm 0.59$ \\
& subtilis & 1.14 & & 1.23 & \\
\hline \multirow{2}{*}{ Fungi } & Candida & $20.45 \pm$ & $6.14 \pm 0.61$ & $22.62 \pm$ & $6.14 \pm 0.61$ \\
& albicans & 1.26 & & 1.28 & \\
\hline
\end{tabular}

Table 7: Zone of inhibition of the optimized formulation (F1).

*Control: Methanolic extract of B. aristata.

From the above mentioned result and by comparing the zone of inhibition values of the test (cream) with the control, it is observed that optimized formulation (F1) has larger zone of inhibition i.e. $24.66 \pm 1.14$ and $26.26 \pm 1.23$ for bacteria and $20.45 \pm 1.26$ and $22.62 \pm 1.28$ for fungi at $250 \mathrm{ppm} /$ disc and $500 \mathrm{ppm} /$ disc respectively. So it may be concluded that the optimized formulation F1 exhibits better antibacterial and antifungal activity.

Skin irritation test data

The skin irritation test was performed to confirm the safety of the herbal formulation. Aqil., et al. [21] mentioned that a value of skin irritancy score between 0 and 2 indicates that the applied formulation is non-irritant and safe for human skin. The mean value of skin irritancy score for formulation was found to be 1.16 (Table 8). This value indicates that all excipients used in formulation were safe for topical drug delivery. 


\begin{tabular}{|c|c|c|c|c|c|c|c|c|}
\hline \multirow{4}{*}{ Rats } & \multicolumn{8}{|c|}{ Skin irritation scores of formulation ( $A$ = Erythema formation score; $B$ = Oedema formation score) } \\
\hline & \multicolumn{4}{|c|}{ Intact skin } & \multicolumn{4}{|c|}{ Abraded skin } \\
\hline & \multicolumn{2}{|c|}{24 hours } & \multicolumn{2}{|c|}{72 hours } & \multicolumn{2}{|c|}{24 hours } & \multicolumn{2}{|c|}{72 hours } \\
\hline & A & B & A & B & A & B & A & B \\
\hline 1 & 0 & 1 & 0 & 1 & 0 & 1 & 1 & 0 \\
\hline 2 & 0 & 0 & 1 & 0 & 0 & 1 & 0 & 1 \\
\hline 3 & 1 & 1 & 0 & 1 & 0 & 2 & 1 & 1 \\
\hline
\end{tabular}

Final skin irritation scores of formulation (* $=$ Total of A and B from part a.; ${ }^{* *}=$ Average of all skin reading of 24 and 72 hours)

\begin{tabular}{|c|c|c|c|c|c|}
\hline \multirow[t]{3}{*}{ Rats } & \multicolumn{2}{|c|}{ Intact skin } & \multicolumn{2}{|c|}{ Abraded skin } & \multirow{3}{*}{$\begin{array}{l}\text { Total Average } \\
\qquad \text { (i)+(ii) }\end{array}$} \\
\hline & \multicolumn{2}{|c|}{24 hours 72 hours } & \multicolumn{2}{|c|}{24 hours 72 hours } & \\
\hline & \multicolumn{2}{|c|}{ (i) } & \multicolumn{2}{|c|}{ (ii) } & \\
\hline 1 & 1 & 1 & 1 & 1 & 1 \\
\hline 2 & 0 & 1 & 1 & 1 & 0.75 \\
\hline \multirow[t]{2}{*}{3} & \multirow[t]{2}{*}{2} & \multirow[t]{2}{*}{1} & \multirow[t]{2}{*}{2} & \multirow[t]{2}{*}{2} & 1.75 \\
\hline & & & & & Combined avg. $=1.16$ \\
\hline
\end{tabular}

Table 8: Scores of formulation (F1).

\section{Conclusion}

From the result of present study, it can be concluded that F1 formulation was optimized from all the batches. FT-IR study revealed that there is no possible drug interaction with other components present in extract and DSC study depicts that berberine is present in the extract. An in vitro drug release study showsF1 releases the drug up to $76.5 \%$ in 12 hour. Release mechanism follows first order kinetics where drug is being released through diffusion process (Higuchi model $\mathrm{R}^{2}=0.9601$ ). The formulation follows Fickian diffusion ( $n=0.2912$ from Korsmeyer-Peppas law equation). Also the formulation is non irritant and can be applied easily. Thus, Berberine based anti-psoriatic cream has great potential for the management of psoriasis.

\section{Acknowledgements}

Authors are thankful to the principal RVNI Greater Noida India, for providing the best research facilities available for conducting the research work. Authors are also thankful for the support provided by Central Instrumentation Facility, Jamia Hamdard, New Delhi.

Authors are also thankful to Director, University Polytechnic, BIT Mesra for his guidance. There is no any conflict of interest among the authors regarding the submission of manuscript.

\section{Bibliography}

1. Tanweer A Syed., et al. "Management of psoriasis with Aloe Vera extract in a hydrophilic cream: a placebo-controlled, double-blind study". Tropical Medicine and International Health 1.4 (1996): 505-509.

2. Kennet GL., et al. "Psoriasis: Current perspectives with an emphasis on treatment". The American Journal of Medicine 107.6 (1990): 595-605.

3. Rakesh K Sindhu., et al. "Psoriasis and herbal care: a brief review". International Journal of Pharma Research and Development 1.9 (2007): 1-8.

4. Goyal S., et al. "Novel Anti-Inflammatory Topical Herbal Gels Containing Withania somnifera and Boswellia serrata". International journal of Pharmaceutical and Biological Archive 2.4 (2011): 1087-1094.

5. Chakravarti KK., et al. "Alkaloidal constituents of the bark of $B$. aristata (Rassaut)". Journal of Scientific and Industrial Research 9B (1950): 161-164.

6. Poornima Agrawal., et al. "Formulation and evaluation of herbal gel containing Boswellia serrata, Curcuma longa extract and oil of wintergreen for rheumatoid arthritis". International Bulletin of Drug Research 2.3 (2012): 31-40. 
7. Bairwa Ranjan., et al. "Standardization and phytochemical investigation of Berberis aristata". Asian Journal of Pharmaceutical Analysis 2.3 (2012): 81-84.

8. Chen QH., et al. "Determination of colchicine in mouse plasma by high performance liquid-chromatographic method with UV detection and its application to pharmacokinetic studies". Yakugaku Zasshi 127.9 (2007): 1485-1490.

9. Hemant Shigwan., et al. "HPLC Method Development and Validation for Quantification of Berberine from Berberis aristata and Berberis tinctorial". International Journal of Applied Sciences and Engineering 11.2 (2013): 203-211.

10. M Shahid., et al. "Ethnobotanical studies on berberis aristata DC Root Extracts". African Journal of Biotechnology 8.4 (2009): 556-563.

11. Namrata Singh., et al. "Formulation and Evaluation of Meloxicam Microspheres Using Eudragit S-100". IJPRS 3.2 (2014) 330-339.

12. Ashish Aswal., et al. "Preparation and evaluation of polyherbal cosmetic cream". Scholars Research Library, Der Pharmacia Lettre 5.1 (2013): 83-88.

13. Gidwani Beena., et al. "Evaluation of a Novel Herbal Formulation in the Treatment of Eczema with Psoralea Corylifolia". Iranian Journal of Dermatology, Winter 134.54 (2010): 122-127.

14. Kumar L and Verma R. "In-vitro evaluation of topical gel prepared using natural polymer". International Journal of Drug Delivery 2 (2010): 58-63.

15. Pasrija Anubhuti., et al. "Comparative study on the antimicrobial activity of berberis aristate from different regions and berberine in- vitro". International Journal of Life Science and Pharma Research 1.1 (2011): 17-20.

16. SA Hussain., et al. "In-vitro Antimicrobial Activity of Polyherbal Formulation". Journal of Pharmaceutical Research and Opinion 1.3 (2011): 94-95.

17. S Alam., et al. "Microemulsion as a Potential Transdermal Carrier for Poorly Water Soluble Antifungal Drug Itraconazole". Journal of Dispersion Science and Technology 31 (2010): 84-94.

18. S Sujith Nair., et al. "Evaluation of Skin Irritation of Herbal Antioxidant Cream". Asian Journal of Biochemical and Pharmaceutical Research 2.3 (2012): 184-189.
19. Arun K Mishra., et al. "Evaluation of Skin Irritation of Herbal O/W Sunscreen Cream on Rabbit Model". IJPI's Journal of Pharmaceutics and Cosmetology 1.3 (2011): 45-49.

20. BH More., et al. "Evaluation for Skin irritancy testing of developed formulations containing extract of Butea monosperma for its topical application". International Journal of Toxicology and Applied Pharmacology 3.1 (2013): 10-13.

21. Aqil M., et al. "Matrix type transdermal drug delivery system of metoprolol tartrate: Skin toxicity and in-vivo characterization". Ethiopian Pharmaceutical Journal 22.1 (2004): 53-60.

\section{Assets from publication with us}

- Prompt Acknowledgement after receiving the article

- Thorough Double blinded peer review

- Rapid Publication

- Issue of Publication Certificate

- High visibility of your Published work Website: www.actascientific.com/ Submit Article: www.actascientific.com/submission.php Email us: editor@actascientific.com Contact us: +919182824667 